\title{
The Impact of Digitization on Product Offerings: Using Direct Digital Manufacturing in the Supply Chain
}

\author{
David Swanson \\ University of North Florida \\ david.swanson@unf.edu
}

\begin{abstract}
To remain competitive, supply chain managers must constantly improve their processes and react to evergrowing and evolving customer preferences in a changing business environment. However, many companies have reached diminishing returns for many of their business processes. Digitization has begun to change product offerings and these changes could be the next great source of competitive advantage for supply chain managers. This research uses a demand supply integration framework to examine direct digital manufacturing (DDM) applications being used to change product delivery to consumers. To test hypotheses, press announcements were collected and analyzed with content analysis. We find that, of the implementations of DDM for delivering products to consumers using digitization, 61\% are demand-side focused innovations, 39\% are supply-side focused innovations, and $9 \%$ are both demand-supply integrated innovations.
\end{abstract}

\section{Introduction}

The options of using digitization to significantly change supply chains and change the delivery of products to consumers have significantly changed since a Harvard Business Review article in 1995 motivated companies to "catch the wave" of innovation available to supply chain managers [1]. Digitization of the supply chain has the potential to dramatically lower costs, increase product availability, and even create new markets unknown or unavailable prior to the availability of key technologies like direct digital manufacturing (DDM). However, in 2013 the Supply Chain Quarterly and IBM reported that supply chain leaders are failing to see how technologies like DDM will impact supply chains [2].

Some research finds that revolutionary applications of DDM are emerging from the nascent stage because organizations are moving from using DDM only for design and prototyping to using DDM to make finished products [3]. DDM technology moves production closer to consumers and by doing so inventory, the number of SKUs, and transportation can be reduced. For example, Amazon is revolutionizing a supply chain by providing retail outlets whereby over 200 products can be printed by customers. By doing this, the supply chain is changed remarkably for several reasons including fewer raw materials, warehousing of finished goods is not required, and neither are shipments to a retail store.

Even though revolutionary changes are being made, the information that has surfaced in the business press gives unclear and sometimes conflicting reports about how far along and influential DDM really is [1][4]. Due to this ambiguity and overly optimistic speculation of DDM [3], theory-driven research is required to explore how revolutionary technologies like DDM will impact supply chain management because their impact is likely to be transformational [5].

This research pursues the research question: whether or not supply chains are being impacted by DDM, and if so, how? Knowing the answer is especially important for supply chain managers who must determine whether or not DDM will play a part in their supply chain strategy to provide products to their customers. Risking delay could mean loss of market share and a cost structure which burdens the organization such that competing is difficult and margins are stressed. Alternatively, advancing into a technology that may never deliver its intended benefits can burden the organization with many of the same issues.

The objective of this research is to build upon the concept of demand and supply integration by looking for theoretical insights to explain and predict how DDM is being used to change the delivery of products. With that in mind, hypotheses are developed and tested with empirical data. For our tests, we collect press announcements from the Lexus/Nexus database on DDM innovations in supply chain practices from a thirteen month period (May 2014 through May 2015), and we analyze them with content analysis. We then provide a discussion of key questions and include opportunities for future research. 


\subsection{Digitization and the Internet of Things}

Digitization and internet capabilities have tremendous impacts for the supply chain. Digitization in the supply chain has been described as being able to take advantage of evolving and newly available technologies to reengineer business processes to gain a competitive advantage [6]. For example, the potential for digitization to revolutionize business processes has reportedly led to new product offerings at General Electric generating \$1 Billion in new sales revenue [6]. Furthermore, there is ample anecdotal evidence that firms are dynamically changing their fundamental supply chain processes and tremendously impacting the way products are provided for customers.

Supply chain managers now have more information to diagnose problems and initiate the most effective and efficient solution. Applications of supply chain information can apply strategic objectives determined by supply chain managers, and then, based on real time information from multiple internet sources, propose a solution. This is often termed an application wizard. Solutions could include things such as inventory purchases, transferring inventory, or transportation routing changes-really any type of supply chain response.

Technology improvements over the last decade have enabled tremendous potential to solve business problems. This potential can improve supply chain efficiency, but doing so is not easy. The new technologies also come with new processes and business models which must be determined and implemented in organizations which do not naturally invite and welcome change. Responding to customers requires keeping up with technological changes and those companies that do not do so will lose their competitive advantage [6].

Digitization is not entirely new in practice, but has perhaps finally reached a critical mass to be defined as a concept. Over ten years earlier, the author designed and installed an internet enabled process for Walmart that fits the definition of Digitization presented earlier. Using the internet, distribution center appointments were given systematically to vendors and carriers bringing inbound shipments. Using Retail Link, Walmart's proprietary intranet that links key supply chain partners, vendors or carriers would enter a load number. Based on the characteristics of that load, the other loads already scheduled, the resources in the distribution center, and the priorities of Walmart managers, the most optimum appointment times are presented to the clerk making the inbound appointment.

Therefore, even though digitization and the Internet of Things may be newly coined terms, the concept and the practice is not new. Yet, companies still have idle inventory and other resources that are not "working” for them. To remain competitive, supply chain managers must constantly improve their processes and react to ever-growing and evolving customer preferences in a changing business environment.

With increasing information capabilities, firms now can better understand how and where their supply chain is working efficiently, and more importantly, where it is not. Supply chain visibility is therefore increased allowing firms to achieve a greater level of performance and competitive advantage.

\subsection{Direct Digital Manufacturing}

DDM is a manufacturing process that operates by adding layers of a material until an item takes shape. It has often been described as the opposite of cutting or sculpting a shape (i.e. subtractive manufacturing) and hence is often known as additive manufacturing. 3D printing is another common term used to describe this manufacturing process. For many years DDM has been used to prototype models and assist product designers. However, now it is becoming a tool and driving new business processes that are being used to deliver products to consumers - a tool that is fundamentally changing supply chains. DDM has tremendous possibilities for reducing inventory and eliminating transportation requirements which are two things that are commonly believed to be mainstays in the supply chain.

\subsection{Active Customers}

Customer participation has been defined as "the active involvement of the customer in the production and delivery of a service, by the contribution of personal resources, which influence processes and outcomes.” [7] For over a decade now, digital technologies have contributed to the enablement of active customers in revolutionary ways [8].

The literature primarily associates active customers with increased uncertainty, because participating customers provide opinions which can be planned for and managed only imperfectly [9] [10]. Now, with DDM, customer empowerment has never been greater. However, even though customers are empowered by DDM technologies, they also have the means to fulfill their additional requests themselves. This means the organization may not have additional uncertainty from this type of increased involvement by the active customer, and this means that new theory needs to be 


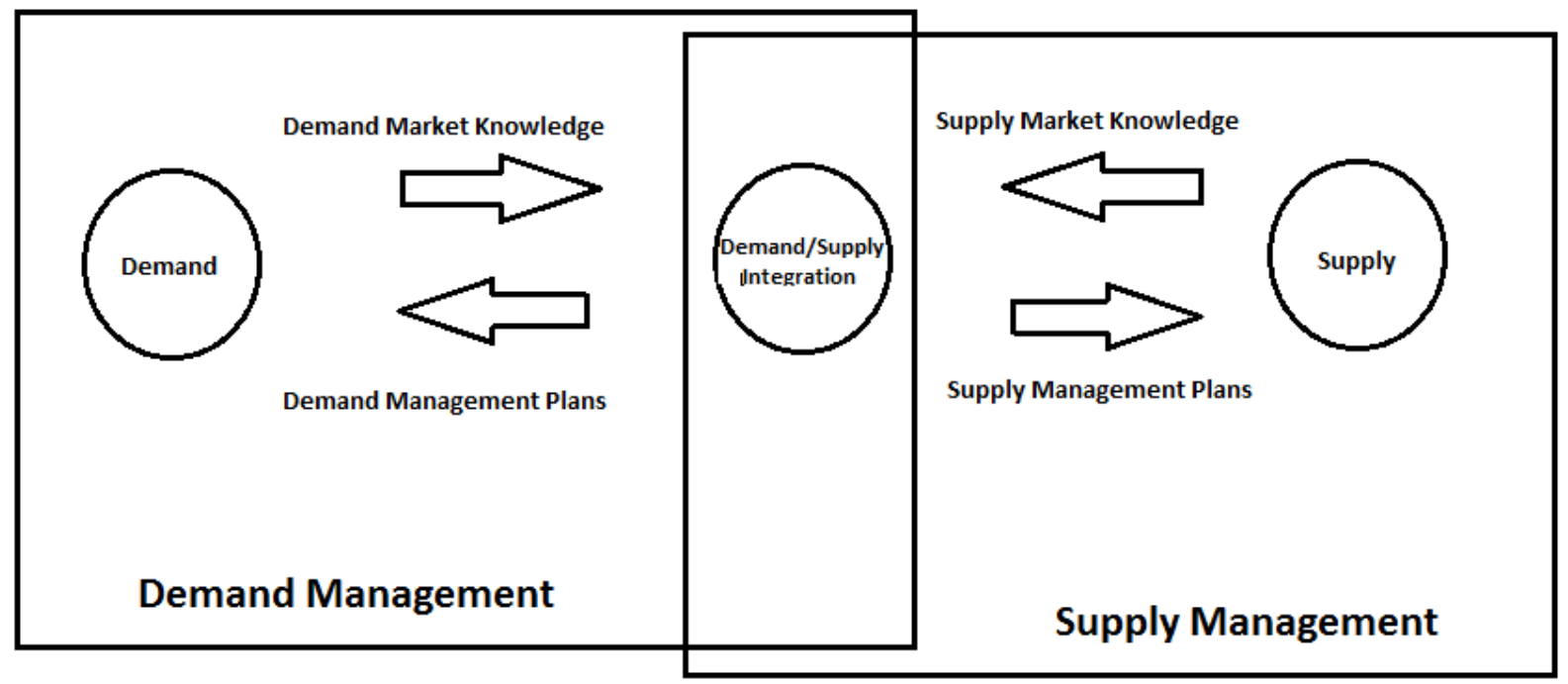

developed to understand this new phenomenon. Note also that DDM has tremendous benefits for customer service and delivering the right product at the right time.

\subsection{Summary}

As digitization and the internet become more refined and powerful, new technologies like DDM will continue to change the way products are distributed to consumers. While doing so, consumers will have more variety from which to choose, better accessibility to have their products when and where they want them most; and all this will be provided at a lower price.

\section{Theoretical Framework}

\subsection{Demand Supply Integration Framework}

The theoretical foundation for this research is provided by using the conceptual framework of demand and supply integration [11] which can add theoretical value to supply chain optimization [12].

Historically, firms that optimize their supply chains will do so by optimizing either end of the supply chain, but not both at the same time [11]. For example, firms will optimize either the delivery to the customer (i.e. demand side) or they will optimize the efficiency and effectiveness of sourcing materials (i.e. supply side). Frankel and Mollenkopf (2015) report that when using a demand and supply integration framework, crossfunctional integration is largely contained within the notion of "demand" functions and "supply" functions
[13]. Like many other functions of logistics (e.g. transportation and inventory management) there are tradeoffs between the functions [14]. Furthermore, demand side and supply side optimization techniques are often in direct conflict with one another. Therefore, it is important to consider both demand and supply side optimization when a firm seeks to optimize its supply chain operations.

A framework for increasing supply chain value creation through demand and supply integration is provided by Esper et al., (2010), and it provides a lens through which this research examines applications of DDM by firms-applications that are designed to improve supply chain performance related to offering of products. Figure 1 shows the conceptual framework of demand and supply integration.

\subsection{Hypotheses}

The theoretical concept of demand supply integration suggests that some supply chain innovations from DDM are related to supply-side processes and some applications would be related to demand-side processes [11]. Accordingly, this research examines the DDM applications in supply chain management for improving the offerings of products to consumers. Since DDM has the potential to change both supply-side processes and demand-side processes, this research hypothesizes:

H1: DDM impacts supply chains by demand-focused strategy. 
H2: DDM impacts supply chains by supply-focused strategy.

However, firms are integrating their demand and supply processes and there is theory that these can be optimized if they are not considered independently [11]. Therefore, we hypothesize that DDM applications designed to change the supply chain by offering products to consumers should also begin to exhibit some examples of demand supply integration. Therefore this research hypothesizes:

H3: DDM impacts supply chains by demand supply integration-focused strategy.

\section{Research Methodology and Results}

\subsection{Data}

Press announcements highlighting DDM innovations between May 2014 and May 2015 were examined to determine if 3D innovations are radically changing supply chains and disrupting existing markets. Data was collected by utilizing the following search terms in Lexus/Nexus: "direct digital manufacturing," "3D printing," and "3-D printing”. The words "product" or "process" also must be included in the press announcement to refine the results with a greater likelihood of finding companies using DDM to manufacture products or to change their business processes. Next, press announcements that included the word "prototype" were excluded, because many of these announcements indicate that DDM has been adopted to create prototypes rather than to produce a final part or good available for sale. Additionally, the Lexus/Nexus option to reduce duplicates of moderate similarity was selected, which yielded 3,212 press announcements that were examined and coded. Supply chain impacting press announcements were read and coded by two researchers.

Beginning in May 2015 the original search terms were returning an exponential number of press announcements. To keep this manageable we used some additional terms to exclude press announcements that included the words: "school," "library," "student," and "college." These terms used were identified by the researchers who were finding many press announcements associated with education which were not related to companies offering existing products.

\subsection{Content Analysis}

This research uses content analysis to glean information from press announcements. Researchers followed content analysis methodology specified by Grotsch et al. (2013) rather than relying on word counts, which is often used in content analysis research [15]. The methodology that was used requires researchers to identify themes of words and determine the underlying concepts. The coding process was made to be less subjective by requiring the researchers to look for specific content in the press announcement, rather than relying solely on their own judgement. For example, to determine if a supply chain was impacted, researchers determined if a company was mentioned in the press announcement that currently is using DDM to deliver a product that is already available for sale. Please see Table 1 which includes the specific information which was looked for in the process of coding the press announcements.

\begin{tabular}{|l|l|}
\hline Table 1 & \\
\hline $\begin{array}{l}\text { Supply Chain } \\
\text { Impact }\end{array}$ & $\begin{array}{l}\text { This variable is used to indicate if the press } \\
\text { announcement revealed evidence of a supply } \\
\text { chain impact. To be coded as a supply chain } \\
\text { impact, the press announcement must identify a } \\
\text { specific company that is manufacturing a } \\
\text { product with DDM that is already for sale in the } \\
\text { marketplace. }\end{array}$ \\
\hline $\begin{array}{l}\text { Demand-focused } \\
\text { Strategy }\end{array}$ & $\begin{array}{l}\text { When press announcements that identify a } \\
\text { supply chain impact use DDM to provide } \\
\text { customized product for consumers or otherwize } \\
\text { use DDM in clearly a customer-centric strategy } \\
\text { they are coded as demand-focused strategies. }\end{array}$ \\
\hline $\begin{array}{l}\text { Supply-focused } \\
\text { Strategy }\end{array}$ & $\begin{array}{l}\text { When press announcements that identify a } \\
\text { supply chain impact use DDM to make products } \\
\text { used in the supply or manufacture of products } \\
\text { that are not tailored to specific consumers they } \\
\text { are coded as supply-focused strategies. }\end{array}$ \\
\hline $\begin{array}{l}\text { Demand Supply } \\
\text { Integration }\end{array}$ & $\begin{array}{l}\text { When press announcements that identify a } \\
\text { supply chain impact use DDM to make products } \\
\text { thar are both used in the supply or manufacture } \\
\text { of products and are tailored to specific } \\
\text { consumers they are coded as strategies that } \\
\text { exhibit evidence of demand supply integration. }\end{array}$ \\
\hline
\end{tabular}

\section{Results and Analysis}

The pilot study finds that the use of DDM in innovative ways to change the supply of products to consumers is increasing significantly. During data analysis of months in 2014 on DDM innovations in supply chains there was a range of innovations from 39 per month. During data analysis of months in 2015 on DDM innovations in supply chains there was a range of innovations from 10 to 44 per month. 


\begin{tabular}{|c|c|c|c|c|c|c|c|c|c|c|c|c|c|}
\hline \multicolumn{14}{|l|}{ Table 2} \\
\hline Year & 2014 & & & & & & & & 2015 & & & & \\
\hline Month & May & Jun & Jul & Aug & Sep & Oct & Nov & Dec & Jan & Feb & Mar & Apr & May \\
\hline Total Press Announcements & 230 & 214 & 170 & 199 & 204 & 243 & 256 & 230 & 268 & 256 & 288 & 300 & 353 \\
\hline Supply Chain Impact & 3 & 3 & 5 & 4 & 4 & 6 & 9 & 3 & 12 & 14 & 12 & 10 & 44 \\
\hline Demand-Focused Strategy & 3 & 2 & 3 & 2 & 3 & 5 & 8 & 3 & 10 & 12 & 5 & 2 & 21 \\
\hline Supply Focused Strategy & 0 & 1 & 1 & 2 & 1 & 1 & 1 & 0 & 1 & 1 & 7 & 7 & 16 \\
\hline Demand Supply Integration & 0 & 0 & 1 & 0 & 0 & 0 & 0 & 0 & 1 & 1 & 0 & 1 & 7 \\
\hline
\end{tabular}

Supply chain impacts were identified in press announcements by searching for evidence that a supply chain was already being impacted. A supply chain impact was identified if a company was using DDM to manufacture a product that was currently for sale. Therefore, press announcements that introduced prototypes and plans of using DDM were not considered impactful. Also, keep in mind that impactful is not necessarily positive. There are challenges with DDM which can be difficult to implement and expensive.

Using the original search terms for finding press announcements the total press announcements collected per month rose from a low of 170 in July 2014 to a high of over 1700 during May 2015. In Table 2 the total press announcements for May 2015 is shown to be 353. This is because we added additional search terms with the objective of filtering out more of the press announcements that didn't have supply chain impacts. This can be seen in the ratio of the number of supply chain impacts found to total press announcements. For example, in April 2015, 11 impacts were found from 300 press announcements, and in May 2015, 44 impacts were found from 353 press announcements. Inter-rater reliability tests were $93 \%$.

This study included a detailed examination of 129 press announcements that indicated a supply chain was altered by using DDM in the supply chain for purposes of distributing an existing product to consumers. Approximately 61\% (i.e. 79/129) of these supply chain impacts were implemented with evidence of a demandfocused strategy. See Table 2. Therefore, H1 is supported. For example, companies are using DDM to make body parts (i.e. bones replacements) in the emergency room to assure a perfect match for the patient (consumer). Other examples include consumer printed earbuds, shoe inserts, and their own bobble-head dolls.

The study also found that supply chain impacts were used to optimize supply-focused strategies as well. Approximately 39\% (i.e. 39/129) of these supply chain impacts were implemented with evidence of a supplyfocused strategy. Therefore, $\mathrm{H} 2$ is supported. In the instances of supply-focused strategies, the supply and distribution of materials was made better, even though the ultimate consumers were not yet known. Also, there was no indication of consumer customization. Examples include printing parts for aircraft engines that lower the cost of manufacture, speed the time of manufacture, or make the quality of the finished product better.

The study also found that supply chain impacts of DDM that were used to change supply chains also showed some indication of demand-supply integration. Demand-supply integration was evident in approximately 9\% (i.e. 11/129) of innovations that changed the delivery of products to consumers. Therefore, H3 is supported.

The first evidence of demand-supply integration in this sample occurred in a July 2014 press announcement by Wentloog, a company in South Wales. In the announcement the company touted its one-millionth DDM printed product, which indicates a strong reliance on DDM in their supply strategy. Wentloog specializes in producing custom made in-ear monitors that are used by musicians, television sound engineers, camera operators, and on-camera personalities. The products are made for individual consumers thereby assuring a perfect inner ear fit. This aspect of their supply chain strategy represents a demand-focused strategy as well.

A second example of demand-supply integrated strategies that involve the use of DDM to impact a particular supply chain include the work and business strategies of Elie Top, a jewelry designer who used DDM to design and manufacture his first collection of jewelry. This represents a business process innovation for supplying jewelry to the market. However, Mr. Top also encourages individual customers to bring their special stones to him and together he and the consumer can design and print customized jewelry that is exactly what the consumer would like to have. See Appendix 7.3 to read the full press announcement.

\section{Conclusion}

\subsection{Summary}

This study finds that firms are revolutionizing their supply chains by using applications of DDM to improve the supply of their products or improve their ability to 
meet consumer demand, confirming that DDM will require firms to rethink their strategies and operations in regard to supply, manufacturing and retailing to remain competitive [16].

\subsection{Limitations}

Even though the press announcement search provided many relevant indications of demand and supply integration, there are likely others. Some supply chain oriented DDM processes are not announced via the press and have remained hidden from our study.

\subsection{Future Research}

In the course of doing this study, several opportunities surfaced for future research on how DDM impacts the supply chain. First, past research has demonstrated that market-oriented logistics has a profound impact on success [17] and we know of the changes regarding active customers. However, future research should answer how a market orientation contributes to creating and maintaining successful deployments of digitization innovations in supply chains. Second, as DDM processes and materials evolve, the growth of DDM applications is compounding [3]. A list of recently patented DDM materials is provided in Appendix 7.4 and it shows the possibilities now extend beyond plastic to multiple types of metal, foam, and edible materials. Future researchers should examine the moderating and mediating relationships between the success of DDM and the availability of complementary enabling technologies. Third, Golicic and Sebastiao (2011) find that value proposition definition and legitimacy drive supply chain strategy in nascent markets and are the means by which initial supply chains are formed [18]. Researchers should explore how these antecedents come into play when management needs to drive the supply chain strategy for introducing innovations in existing markets.

\section{References}

[1] Bower, J. L. \& Christensen, C. M. (1995). Disruptive Technologies: Catching the Wave. Harvard Business Review, 73(1), 43-53.

[2] Brody, P. (2013) "Get ready for the "software-defined supply chain," The Supply Chain Quarterly, Quarter 42013. Accessed online:

http://www.supplychainquarterly.com/topics/Manufacturing/ 20140110-get-ready-for-the-software-defined-supply-chain/.
[3] Gartner (2014). “Gartner says consumer DDM is more than five years away.”

https://www.gartner.com/newsroom/id/2825417. Accessed August 7, 2015.

[4] Price Waterhouse Coopers, "DDM and the new shape of industrial manufacturing,” PWC Whitepaper, June 2014.

[5] Fawcett, S. E., \& Waller, M. A. (2014). Can We Stay Ahead of the Obsolescence Curve? On Inflection Points, Proactive Preemption, and the Future of Supply Chain Management. Journal of Business Logistics, 35(1), 17-22.

[6] Gilmore, D. (2016). "Supply Chain Thought Leaders Video Series: Important Trends in Supply Chain DSupply Chain Digest, June 1, 2016 (Accessed online at: http://www.scdigest.com/NEWSVIEWS/16-06-021.PHP?CID=10776)

[7] Büttgen, M., \& Ates, Z. (2009). Customer participation and its effects on service organisations: An institutional economics perspective. In Proceedings of the 2009 Naples Forum on Service (pp. 1-45).

[8] Slywotzky, A., \& Morrison, D. (2001). The rise of the active customer. Marketing Management, 10(2), 22.

[9] Legnick-Hall, C. (1996). "Customer Contributions to Quality: A Different View of the Customer-Oriented Firm.” Academy of Management Journal, 21(3), 791-824.

[10] Larsson, R., \& Bowen, D. E. (1989). Organization and customer: managing design and coordination of services. Academy of Management Review, 14(2), 213-233.

[11] Esper, T. L., Ellinger, A. E., Stank, T. P., Flint, D. J., \& Moon, M. (2010). Demand and supply integration: a conceptual framework of value creation through knowledge management. Journal of the Academy of marketing Science, 38(1), 5-18.

[12] Mentzer, J. T., \& Gundlach, G. (2010). Exploring the relationship between marketing and supply chain management: introduction to the special issue. Journal of the Academy of Marketing Science, 38(1), 1-4.

[13] Frankel, R., \& Mollenkopf, D. A. (2015). CrossFunctional Integration Revisited: Exploring the Conceptual Elephant. Journal of Business Logistics, 36(1), 18-24.

[14] Lambert, D, Stock, J., and Ellram, L. "Fundamentals of Logistics Management.” Irwin McGraw-Hill, Boston, MA.

[15] Grötsch, V. M., Blome, C., \& Schleper, M. C. (2013). Antecedents of proactive supply chain risk management-a 
contingency theory perspective. International Journal of Production Research, 51(10), 2842-2867.

[16] D'aveni, R. A. (2013). 3-D printing will change the world. Harvard Business Review, 91(3), 34-35.

[17] Fúgate, B. S., Flint, D. J., \& Mentzer, J. T. (2008). The role of logistics in market orientation. Journal of Business Logistics, 29(2), 1-26.

[18] Golicic, S. L., \& Sebastiao, H. J. (2011). Supply chain strategy in nascent markets: the role of supply chain development in the commercialization process. Journal of Business Logistics, 32(3), 254-273.

\section{Appendix A: Examples of Press Announcements}

\subsection{Example of Press Announcement Identified as Supply-focused Strategy}

[The aircraft manufacturing process used by Airbus identified in the press announcement below includes over 100 parts that are now being printed with DDM. This changes the supply chain that surrounds these parts, because printing them precludes sourcing relationships and advanced inventory management of raw materials. This process ultimately will result in a better delivery of products to consumers, even if it is indirectly reflected in a lower price or better quality. However, since it is not being done specifically for an individual customer this is an example of a supplyfocused strategy.]

SP airBUZ.net

May 7, 2015

"Stratasys additive manufacturing solutions selected by Airbus to produce 3D printed flight parts for its A350 XWB aircraft”

Stratasys Asia Pacific, a subsidiary of Stratasys Ltd. (Nasdaq:SSYS), a leading global provider of 3D printing and additive manufacturing solutions, announces that leading aircraft manufacturer Airbus has produced more than 1000 flight parts on its Stratasys FDM 3D Production Systems for use in the first-of-type A350 XWB air-craft, delivered in December 2014. The 3D printed parts were used in place of traditionally manufactured parts to increase supply chain flexibility, enabling Airbus to meet its delivery commitment on-time. Airbus initiated development and certification of 3D printing with Stratasys in 2013 as a schedule risk reduction activity that proved valuable for the A350 XWB program, highlighting a key benefit of 3D printing in the manufacturing industry.

The parts are 3D printed using ULTEM 9085 resin for FDM, which is certified to an Airbus material specification. UL-TEM 9085 resin provides high strength-to-weight ratio and is FST (flame, smoke, and toxicity) compliant for aircraft interior applications. This enables Airbus to manufacture strong, lighter weight parts while substantially reducing production time and manufacturing costs.

"We are delighted that Stratasys additive manufacturing solutions are being adopted by Airbus for its flagship A350 XWB aircraft. Both companies share a vision of applying innovative technologies to design and manufacturing to create game-changing benefits," said Dan Yalon, Executive Vice President, Business Development, Marketing and Vertical Solutions for Stratasys. "Our additive manufacturing solutions can produce complex parts on-demand, ensuring on time delivery while streamlining supply chains. Additive manufacturing also greatly improves the buy-to-fly ratio as significantly less material is wasted than with conventional manufacturing methods. Stratasys is looking forward to bringing these and other advantages to its collaboration with Airbus and to being part of Airbus' Factory of the Future initiative.

[15] ASTM International. (2012) Standard Terminology for Additive Manufacturing Technologies (ASTM F2792-12a), Retrieved from ASTM Online.

\subsection{Example of Press Announcements Identified as Demand-focused Strategy}

[The braille phone described in the press announcement below is being manufactured with DDM with custom programmed keyboards for individual customers, thereby delivering better products to consumers. This is an example of a demand-focused strategy.]

EFYtimes.com

May 19, 2014 Monday 6:30 AM EST

Braille Phone For The Visually Impaired Goes On Sale!

Saurabh Singh

The front and back portion of the device are built using 3D printing techniques to help keep the cost under Pound 60 .

Monday, May 19, 2014: In a bid to provide an instant connection between blind users and their friends and family, OwnFone, a London-based company has come up with the first-of-its-kind Braille phone. Brainchild of Tom Sunderland, the device features a 3D printed keypad consisting of 2/4 braille buttons that are pre-programmed to call important 
people in case of emergency. The device is now available for grabs in the UK at a price of Pound 60 (roughly around Rs 6,000).

The front and back portions of the device are built using 3D printing techniques to help keep the cost under Pound 60 . "The phone can be personalised with two or four Braille buttons which are pre-programmed to call friends, family, or the emergency services," Sunderland was quoted as saying. The device is highly customisable and comes in a variety of colours.

For those who cannot read Braille, the company gives an option of printed raised text on the keypad. "This is the first phone to have a 3D-printed keypad and for people that can't read Braille, we can print texture and raised text on the phone. Our 3D phone printing process is patent pending," Sunderland added.

\subsection{Example of Press Announcements Identified as Demand and Supply Integration-focused Strategy}

[Since the jeweler in this press announcement uses DDM for printing their standard collection each year, and for doing custom work for consumers, this is an example of a company that is using DDM technology for demand supply integration.]

The New York Times

May 14, 2015 Thursday

The New York Times on the Web

Elie Top: Creating His Own Jewelry Line

PARIS -- In January, Elie Top, best known as the jewelry designer for Lanvin, introduced Maison Elie Top and its first collection, Mécaniques Célestes.
This interview with Elie Top was conducted and condensed by Nazanin Lankarani.

What was the advantage of using 3-D printers in producing these pieces?

I had worked with 3-D printing before, in my jewelry for Lanvin, but we went much further here. The precision I needed for this collection could not be done manually without becoming a real nightmare.

The precision that 3-D technology gives you is terrifying The resin model produced is very accurate, but can still be corrected. It is a great tool for visualizing volume, size and wearability of an object. It gives you great control.

Of course, the polishing and stone setting are done manually. A purely machine-made product is not interesting. The pieces are a mixture of both high-tech and manual craftsmanship. $\cdots$

How is this work different from the costume jewelry you design for Lanvin?

The technical possibilities are vast with materials like gold and silver, compared to brass and pewter. Here, we were able to micro-solder in infinitely meticulous detail, something you cannot do in costume jewelry without making your pieces extremely fragile.

The other difference was that there was no collection of clothes to add context to the jewelry. The pieces had to function as stand-alones. I still pictured a silhouette, but without the constraints of the shape of a dress. The materials had to be more precious so the jewelry would have heft on its own.

What is the next step for your brand?

I plan to do one collection a year. In parallel, I would like clients to bring me their own stones or their grandmother's jewelry so we can transform the piece together. I like the idea of taking something old, precious and ancient and putting it inside something new. There is nothing more satisfying than seeing a woman wear a piece you have designed. 